\title{
UnivCloud Project - An innovative concept of a privative Cloud Community
}

\author{
Frédérick BIGRAT ${ }^{1,}$ Dr Bernard Etlicher ${ }^{2}$ \\ ${ }^{1}$ First Class Research Engineer / Project Manager in Paris Île-de-France Digital University \\ University of Paris 1 Panthéon-Sorbonne \\ 12, place du Panthéon 75231 Paris cedex 5 \\ frederick.bigrat@unpidf.fr \\ ${ }^{2}$ Professor of University / Co-Director of Paris Île-de-France Digital University \\ University of Paris-West Nanterre la Défense \\ 200, avenue de la République 92001 Nanterre cedex \\ bernard.etlicher@u-paris10.fr

\section{Keywords} \\ UnivCloud, Cloud Computing, Private Cloud Community, Innovation.
}

\section{ABSTRACT}

Paris île-de-France Digital University (UNPIdF) was created in 2006 following the 2003 call for proposals on regional digital universities. It is attached to the University of Paris 1 PanthéonSorbonne, and potentially represents over 500,000 students (25\% of French students) and around 50,000 academic and administrative staff (about a third of national staff).

The objectives of the UnivCloud project are to define a shared Cloud community platform for the public sphere, to ensure effective management of IT security and system dependability, to analyze uses in order to provide decision support for the infrastructure's everyday running and capacity management, to offer collaborative, shared tools for use by several institutions and to optimize the resources required for the system's operation (energy, IT equipment, etc.)

The project team will present each stage of the project in detail, including its deliverables, the difficulties it presents in terms of organization and skills, a brief comparison to similar approaches in other European countries and the latest results achieved by the Demonstrator.

UnivCloud project is contributing to the development of a competitive Cloud computing solution equal to the challenge of managing computing and data infrastructure within France's Higher Education system.

\section{UNIVCLOUD PROJECT}

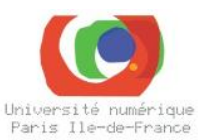

Paris île-de-France Digital University (UNPIdF) was created in 2006 following the 2003 call for proposals on regional digital universities. It is attached to the University of Paris 1 PanthéonSorbonne, and potentially represents over 500,000 students (25\% of French students) and around 50,000 academic and administrative staff (about a third of national staff). UNPIdF has actively ensured the consistent development of pooled digital and online services, equipment, staff training and user support for all 36 of its partners.

Its facilitation of emerging projects and its efforts to develop strong links between institutions make it a driving force within the Paris region's Higher Education and Research community. 
UNPIdF purpose is to provide all the support its members require for the harmonious and coherent development of virtual learning and management systems on a regional scale. It has enabled the deployment of many digital services, including the multi service card, Digital Work Environments (ENTs), the Digital User Guide, mobile services and a whole series of customised training courses for academic and administrative staff. Now, the flagship UnivCloud consultancy project is capitalising on the collaborative approach of the Paris region's universities.

\section{UnivCloud}

In April 2011, with the support of the company COFELY INEO from the GDF-SUEZ Group and four innovative SMEs, UNPIdF successfully tendered its "UnivCloud" consultancy project in a government call for proposals, part of the "Development of the Digital Economy" section of the government's investment programme. The call for proposals provided for the launch of eighteen collaborative R\&D projects involving companies and research institutions in the field of cloud computing. The innovative concept of a Private Cloud Community should help to streamline information systems and digital infrastructure on an institutional scale. This streamlining will be made all the more effective by the possibility of using the applications in SaaS mode.

Consultancy project schedule:

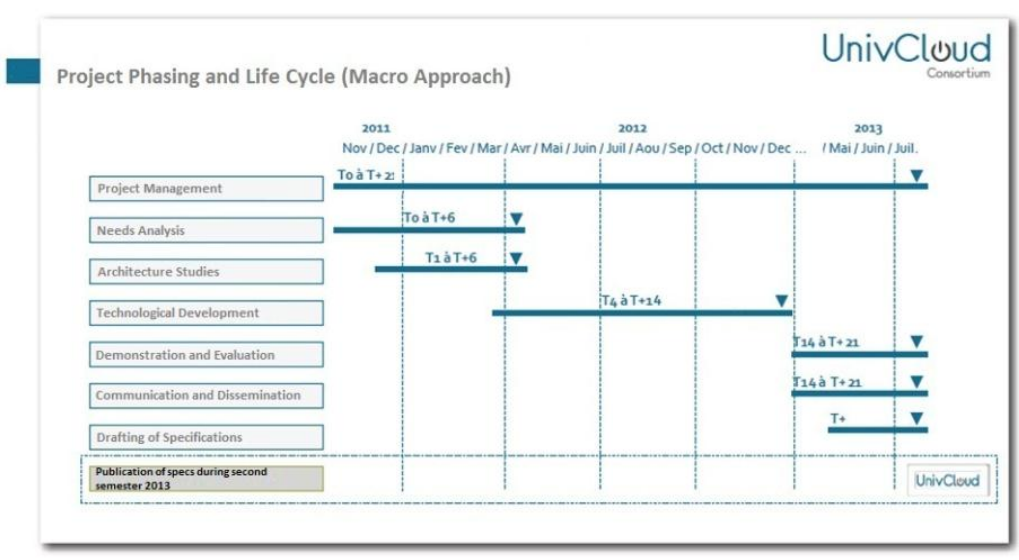

The objectives of the consultancy project are to define a shared Cloud community platform for the public sphere, to ensure effective management of IT security and system dependability, to analyse uses in order to provide decision support for the infrastructure's everyday running and capacity management, to offer collaborative, shared tools for use by several institutions and to optimize the resources required for the system's operation (energy, IT equipment, etc.)

This project addresses issues which affect the whole Higher Education and Research community from three different angles: Technological, with a rationalisation of hosting infrastructures and capacity management; Economic, with cost control and billing per service; and Governance, with the implementation of a coherent, agile governance structure on a regional scale.

Organization and management are carried out at two levels, within the consortium and within UNPIDF itself. The monitoring process is based on alternate bi-monthly coordination meetings. A technical committee monitors the general progress of the project and validates the execution strategy on the basis of proposals/presentations submitted to it, and the inter-WG group works on cross-functional issues. We have set up 30 needs-based Working Groups, covering strategic topics such as Digital Confidence, Governance and Business Model and the uses of the Demonstrator. 
Organisational Structure:

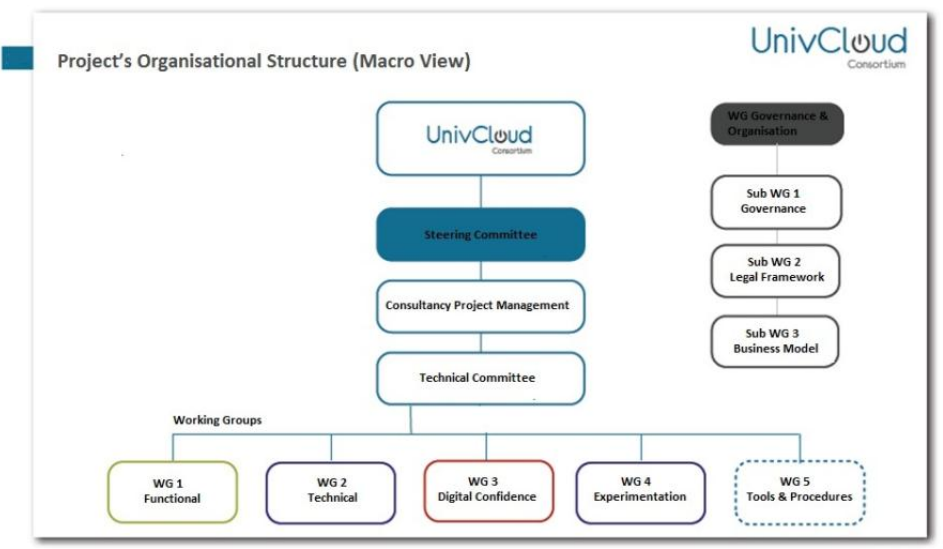

A demonstrator has been established on two sites since March 2013, one hosted by Paris Descartes University and the other by Evry Val-d'Essonne University and ENSIIE. The sites are connected by RENATER, the national academic private network, to enable redundancy and SLA analysis between the two sites. The demonstrator serves several purposes at once: it is an experimental system for testing the results of our partners' R\&D studies, an evaluation platform to keep the UNPIDF community informed of the potential benefits and applications of cloud technology for their respective institutions, a showcase for the future community infrastructure, and a deliverable to be completed within a limited time frame.

This device alone highlights the difficult balance that has had to be found between the technological building blocks provided by our partners, the momentum contributed by the initiatives of the freeware community, the stability guaranteed by industrial platforms and the volume of specific developments to be achieved.

Architecture of the Demonstrator:

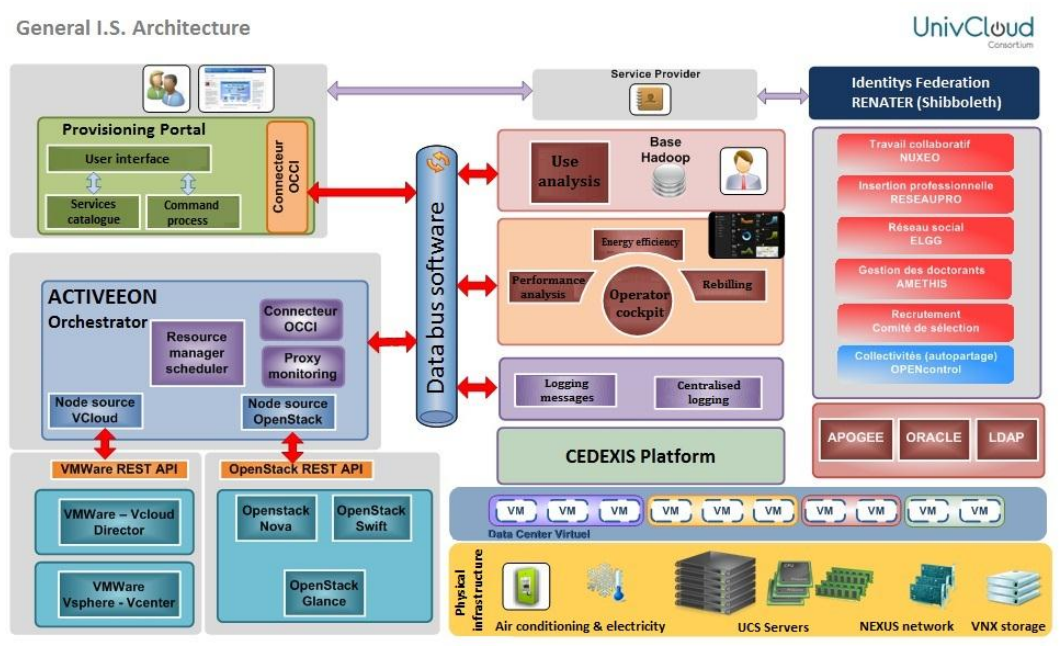

The project team will present each stage of the project in detail, including its deliverables, the difficulties it presents in terms of organisation and skills, and the latest results achieved by the Demonstrator.

Once the UnivCloud study is completed, all the work carried out within the Consortium will be made public and the Consortium will be dissolved as a legal entity. The progress of work on UNPIdF governance, particularly the economic part, will determine the time of publication of the tender and the implementation schedule for the future UnivCloud Environment. This scheme is designed to ensure that all UNPIdF partners keep up with international competition in the higher education and 
research sector. It also aims to pave the way for the development of synergies with other public sector institutions, in particular local authorities. In this way, the UnivCloud project is contributing to the development of a competitive Cloud computing solution equal to the challenge of managing computing and data infrastructure within France's Higher Education system.

\section{REFERENCES}

Bigrat, F. (2012). Security and privacy in the UnivCloud project. Paris, University of Paris Descartes. JRSSI 2012, from : http://www.renater.fr/journees-rssi-2012-a-paris-les-20-et-21-novembre

Bigrat, F. (2013). From Broca to the Cloud, a challenge for Superior Education. Paris, Palais des Congrés. RUE 2013, from : http://youtu.be/NOPBe4isXw0

Bigrat, F. (2013). Identity and access management in the UnivCloud project. Paris, University of Paris1 Panthéon-Sorbonne. JFI 2013, from :

https://services.renater.fr/federation/formations/journee-federation-2013

Etlicher, B. (2013) Cloud and Research, round table, Etats Generaux EuroCloud Paris.

\section{AUTHOR'S BIOGRAPHIES}

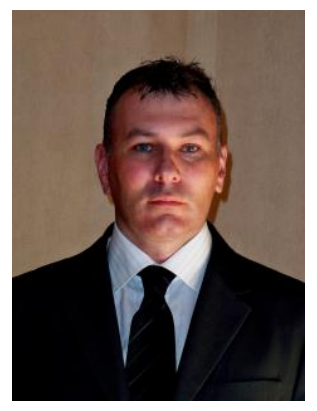

After a career of 15 years as a Network and System Administrator at the French Department of Defense - Land Army, Frédérick BIGRAT joined a private Group (Neurones) and at first worked at the Institute of Research for Development (IRD) as a Network and System Engineer in the SSI division of the DSI for 3 years, and after in Commissariat for Atomic Energy (CEA) for 2 years and 5 months as a Project Leader and Technical Advisor. Actually, Frédérick Bigrat has been First Class Research Engineer and Project Manager specialized in administration and management of complex technical Information System projects in higher education and research in Paris île-de-France Digital University since march 2010. Titular of a Master MIAGE, he is a PhD Student in Information Sciences and Communication at University of Paris West Nanterre la Défense in laboratory TACTIC - EA 1738. Frédérick Bigrat is the project Manager of the UnivCloud project.

frederick.bigrat@unpidf.fr

fr.linkedin.com/pub/frédérick-bigrat/69/a72/b37/

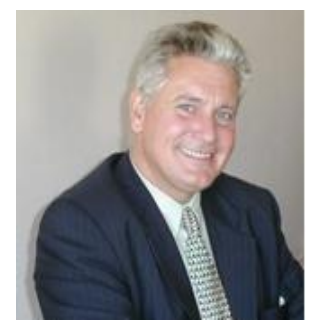

After a PhD obtained in 1979, Bernard Etlicher joined the CNRS and has spent more than 20 years doing plasma physics research at Ecole Polytechnique as a directeur de recherche. After a few years in the state regional administration, he specialized in information system and teaching project and SI management at Paris Ouest Nanterre La Defense University. In parallel, he has been engaged in Paris île-de-France Digital University since January 2011 as a member of the Directorate. Bernard Etlicher is the initiator of the UnicvCloud project and one of the major investigators.

bernard.etlicher@u-paris10.fr

fr.linkedin.com/pub/bernard-etlicher/19/3b0/3b8/ 